Cahiers $d u$ MONDE RUSSE

\section{Cahiers du monde russe}

Russie - Empire russe - Union soviétique et États indépendants

$50 / 4 \mid 2009$

Varia

\title{
Le tournant de la politique religieuse de Stalin
}

Pouvoir soviétique et Église orthodoxe de 1943 à 1945

A turning point in Stalin's religious policy. Soviet power and the Orthodox Church between 1943 and 1945

\section{Adriano Roccucci}

\section{(2) OpenEdition}

\section{Journals}

Édition électronique

URL : https://journals.openedition.org/monderusse/9913

DOI : 10.4000/monderusse. 9913

ISSN : $1777-5388$

\section{Éditeur}

Éditions de l'EHESS

Édition imprimée

Date de publication : 15 décembre 2009

Pagination : 671-698

ISBN : 978-2-7132-2261-0

ISSN : $1252-6576$

\section{Référence électronique}

Adriano Roccucci, «Le tournant de la politique religieuse de Stalin », Cahiers du monde russe [En ligne], 50/4 | 2009, mis en ligne le 14 janvier 2013, consulté le 04 septembre 2022. URL : http:// journals.openedition.org/monderusse/9913; DOI : https://doi.org/10.4000/monderusse.9913 


\section{LE TOURNANT DE LA POLITIQUE RELIGIEUSE DE STALIN}

\section{Pouvoir soviétique et Église orthodoxe de 1943 à 1945}

L'année 1943 marqua un tournant dans la politique religieuse de Stalin. De 1917 à 1939 une impitoyable offensive contre l'Église russe orthodoxe avait été perpétrée en Union soviétique. Son coût humain avait été particulièrement élevé. Une évaluation vraisemblable du nombre de victimes des persécutions contre l'Église orthodoxe estime que cinq cent mille à un million de chrétiens orthodoxes furent tués en raison de leur foi ${ }^{1}$. Les structures ecclésiastiques furent presque totalement anéanties, les séminaires, les écoles théologiques et les monastères, liquidés. Dans l'ensemble de l'Union soviétique, il ne restait en 1939 qu'à peine mille églises consacrées : 97,6\% de celles actives en 1916 avaient été fermées ${ }^{2}$. L'ensemble du corps de l'Église patriarcale ne comptait plus que quatre évêques libres d'exercer leur ministère. Les persécutions sanglantes, la liquidation systématique des règles qui avaient régi la vie de la société russe depuis des siècles, la destruction massive d'édifices et d'objets du culte, un discours public monopolisé par la propagande, le plus souvent agressive, de l'athéisme étaient autant de faits qui avaient bouleversé la vie religieuse des citoyens soviétiques. Le projet bolchevik de liquidation totale des institutions ecclésiastiques, mais aussi de la dimension religieuse comme composante fondamentale de la société et de la personne, demeurait, même après

1. Cf. Nikolaj E. Emel'janov, «Ocenka statistiki gonenij na russkuju pravoslavnuju cerkov’ v $\mathrm{xx}$ veke [Une évaluation de la statistique des persécutions contre l'Église orthodoxe russe au $\mathrm{XX}^{\mathrm{e}}$ siècle] », in Ežegodnaja Bogoslovskaja Konferencija Pravoslavnogo Sviato-Tihonovskogo Bogoslovskogo Instituta. Materialy $1997 \mathrm{~g}$. [Conférence théologique annuelle de l'Institut théologique orthodoxe Saint-Tihon. Matériaux de 1997], M. : Izdatel'stvo Pravoslvanogo Sviato-Tihonovskogo Bogoslovskogo Instituta, 1997, p. 166-168.

2. Cf. Anna Dickinson, «Quantifying Religious Oppression: Russian Orthodox Church Closures and Repression of Priests 1917-1941 », Religion, State \& Society, 28 (4), 2000, p. 327-335. 
1939, l'objectif ultime auquel continuait de tendre le pouvoir soviétique en matière religieuse. Pourtant, l'expansion de l'Union soviétique après le pacte MolotovRibbentrop, le début de la Seconde Guerre mondiale et l'annexion de nouveaux territoires occidentaux - où l'activité religieuse restait vivace et les institutions ecclésiastiques encore florissantes - , favorisèrent le changement de stratégie qui détermina en 1943 le tournant dans la politique religieuse de Stalin, en particulier à l'égard de l'Église orthodoxe.

L'étude de la politique religieuse et de la vie de l'Église orthodoxe russe à partir de 1943 ne peut se fonder quasi exclusivement que sur des fonds d'archives de provenance soviétique ; les archives ecclésiastiques restent encore inaccessibles aux chercheurs ${ }^{3}$. Les archives du Conseil pour les affaires de l'Église russe orthodoxe (Sovet po delam Russkoj pravoslavnoj cerkvi pri Sovete narodnyh komissarov SSSR, ci-après SPDRPC) et celles du Comité central du parti communiste constituent les principales sources exploitées par les chercheurs sur le sujet depuis une vingtaine d'années. Le présent article s'appuie sur ces mêmes sources ${ }^{4}$.

\section{Politique religieuse et horizons géopolitiques}

Dans la nuit du 4 au 5 septembre 1943, se tint au Kremlin une rencontre singulière et paradoxale entre les autorités suprêmes de l'État et les autorités de l'Église orthodoxe russe. Stalin reçut dans son bureau le métropolite de Moscou et de Kolomna, Sergij (Stragorodskij), locum tenens du trône patriarcal, le métropolite de Leningrad

3. Alors que pour les années 1920 et en partie pour les années 1930, abondent les documents produits par des ecclésiastiques, qui, même soumis à diverses mesures de restriction de liberté ne cessaient, dans la mesure du possible, d'écrire, pour les années 1940 et 1950, les documents d'origine ecclésiastique sont plutôt rares. Une grande partie des protagonistes de la vie de l'orthodoxie russe avait été liquidée par la répression ; les survivants, - principaux interprètes de la vie ecclésiale après 1943 - rendus probablement plus prudents par l'expérience vécue, n'étaient pas particulièrement enclins à laisser des témoignages écrits.

4. De nombreuses publications de documents du SPDRPC ont été présentées par Mihail I. Odincov dans la revue Istoričeskij Arhiv. Parmi les autres recueils de documents, voir aussi : Ol'ga Ju. Vasil'eva, Ivan I. Kudrjavcev, Ljudmila A. Lykova, éds., Russkaja Pravoslavnaja Cerkov'v gody Velikoj Otečestvennoj vojny. 1941-1945 gg. : Sbornik dokumentov [L'Église orthodoxe russe pendant la Grande Guerre patriotique, 1941-1945. Recueil de documents], M. : Izdatel’stvo Krutickogo Podvor’ja-Obščestvo ljubitelej cerkovnoj istorii, 2009 ; Natal’ja A. Krivova, éd., Piśma patriarha Aleksija I v Sovet po delam Russkoj pravoslavnoj cerkvi pri Sovete narodnyh komissarov [Lettres du patriarche Aleksij ${ }^{\mathrm{er}}$ au Conseil pour les affaires de l'Église orthodoxe russe auprès du Conseil des commissaires du peuple], M. : Rosspen, 2009. En revanche, les archives de la police politique pour les années qui nous intéressent restent inaccessibles à l'étude. Pour une synthèse de l'historiographie, on s'en référera à Mihail V.Škarovskij, « Stalinskaja religioznaja politika i Russkaja Pravoslavnaja Cerkov`v 1943-1953 godah [La politique religieuse de Stalin et l'Église orthodoxe russe au cours des années 19431953] », Acta Slavica Iaponica, ${ }^{\circ} 27,2009$, p. 1-27, en particulier p. 4-9. Les archives régionales conservent également une documentation d'intérêt remarquable : cf. Daniel Peris, « "God is now on our Side": The Religious Revival on Unoccupied Soviet Territory during World War II », Kritika: Explorations in Russian and Eurasian History, 1 (1), 2000, p. 97-118 ; Sergej A. Čebotarev, Tambovskaja eparhija 40-60 gg. XX veka [L'Éparchie de Tambov pendant les années 1940-1960], Tambov : Julis, 2004. 
et de Novgorod, Aleksij (Simanskij), et le métropolite de Kiev et de Galič, Nikolaj (Jaruševič), en présence de Vjačeslav M. Molotov, du chef du NKGB, Vsevolod N. Merkulov, et du colonel Georgij G. Karpov, responsable du cinquième département de la deuxième section du NKGB, chargé, entre autres missions, du contrôle et de la répression des organisations religieuses ${ }^{5}$. C'est une entrevue cordiale, presque surréaliste, qui se déroule entre celui qui avait violemment poursuivi l'anéantissement total de l'Église et celui qui en avait subi les persécutions et avait vu mourir des centaines de milliers de fidèles sur ordre du premier.

Stalin se montra disposé à écouter les exigences de l'Église présentées par les trois métropolites, depuis celle relative à l'ouverture d'instituts théologiques pour la formation de nouveaux prêtres, jusqu'à celle concernant les besoins économiques de l'Église. Mais surtout, il consentit à la convocation du concile des évêques pour l'élection d'un nouveau patriarche, convocation qu'il avait interdite depuis le décès du patriarche Tihon (Bellavin) en 1925. Stalin entendait rénover le cadre des relations entre l'État et l'Église. C'est dans ce dessein qu'il annonça, au cours de cette rencontre, la création d'un nouvel organe, le Conseil pour les affaires de l'Église orthodoxe russe (SPDRPC), qui devait jouer le rôle d'intermédiaire entre le gouvernement et le Patriarcat ${ }^{6}$.

Le concile des évêques de l'Église orthodoxe russe se réunit à Moscou le 8 septembre. Dix-neuf évêques y participèrent ${ }^{7}$. Tous les prélats qui se trouvaient dans les territoires non occupés de l'Union soviétique y étaient conviés. La majorité d'entre eux avait traversé des périodes plus ou moins longues d'exil ou d'emprisonnement. Sergij, l'ecclésiastique désormais âgé qui avait défendu avec ténacité l'unité canonique de l'Église autour du gouvernement ecclésiastique qu'il dirigeait, fut élu par acclamation patriarche de Moscou et de toutes les Russies ${ }^{8}$.

5. D'après le registre des visiteurs du bureau de Stalin, l'entretien se déroula de minuit quarante à deux heures du matin, cf. « Posetiteli kremlevskogo kabineta I.V. Stalina : Žurnaly (tetradi) zapisi lic, prinjatyh pervym gensekom. 1924-1953 gg. [Les visiteurs du bureau de I.V. Stalin au Kremlin. Registres (cahiers) des personnes reçues par le premier secrétaire général. 19241953] », Istoričeskij Arhiv, n 3, 1996, p. 78.

6. Le procès-verbal de la rencontre est transcrit dans le document « Rapport de G.G. Karpov sur la réception des hiérarques de l'Église orthodoxe russe par I.V. Stalin », septembre 1943, sekretno [secret], GARF (Gosudarstvennyj Arhiv Rossijskoj Federacii - Archives d'État de la Fédération de Russie), f. 6991, Sovet po delam religii pri Sovete Ministrov SSSR, 1943-1991 [Conseil pour les affaires religieuses près le Conseil des ministres de l'URSS, 1943-1991], op. 1, Sovet po delam russkoj pravoslavnoj cerkvi pri Sovete Ministrov SSSR [Conseil pour les affaires de l'Église orthodoxe russe près le Conseil des ministres de l'URSS], d. 1, 1. 1-10. Le document a été publié intégralement dans M.I. Odincov, Russkie patriarhi XX veka : Sud’by Otečestva i Cerkvi na stranicah arhivnyh dokumentov [Les patriarches russes du XX siècle : les destins de la patrie et de l'Église dans les pages des documents d'archives], I ${ }^{\text {re }}$ partie, « Delo » patriarha Tihona ; Krestnyj put' patriarha Sergija [ $L$ ' « affaire » du patriarche Tihon ; le chemin de croix du patriarche Sergij], M. : Izd-vo RAGS, 1999, p. 283-291.

7. Voir : «Dejanija Sobora Preosvjaščennyh Arhiereev Russkoj Pravoslavnoj Cerkvi 8 sentjabrja 1943 goda [Actes du concile des évêques de l'Église orthodoxe russe, 8 septembre 1943] », Žurnal Moskovskoj Patriarhii, n ${ }^{\circ}$, 1943, p. 17-18.

8. Sur la figure de Sergij, voir Sergej Fomin, éd., Straž doma Gospodnja : Patriarh Moskovskij i vseja Rusi Sergij (Stragorodskij) : Žertvennyj podvig stojanija v istine pravoslavija [Le gardien 
Quelles furent les motivations qui poussèrent Stalin à faire ce pas en direction de l'Église orthodoxe russe et à changer ainsi la ligne directrice de sa politique ecclésiastique ? La renaissance religieuse dans les territoires occupés par les Allemands et dans les zones restées sous domination soviétique, le désir de stimuler ultérieurement l'action de l'Église au soutien de l'effort de guerre du pays, l'intention de récompenser d'une façon ou d'une autre la loyauté et le patriotisme du Patriarcat pendant la guerre, la nécessité d'aller au-devant des demandes de l'opinion publique anglaise et américaine à la veille de la conférence de Téhéran pour favoriser l'ouverture d'un second front, les exigences de la politique étrangère, telles sont les raisons majoritairement retenues par les chercheurs ${ }^{9}$.

La reprise de la vie religieuse dans les premières années de guerre et la réouverture massive des églises dans les territoires sous occupation nazie n'avaient pas manqué de réveiller une certaine inquiétude au sein des organes de l'État et du parti. La nécessité se faisait clairement ressentir, en particulier de la part du NKGB, de dépasser une improvisation dictée par l'urgence de la guerre et de redessiner la ligne de la politique religieuse. Placer la vie de l'Église sous contrôle était un objectif inhérent à la logique même du régime stalinien, qui ne concevait pas au sein de l'Union soviétique l'existence de secteurs de la vie sociale susceptibles de se soustraire à la surveillance des autorités du pays. Un tel résultat aurait pu s'obtenir sans pour autant accorder à l'Église des concessions d'ampleur inhabituelle pour le régime stalinien. L'action patriotique des ecclésiastiques avait probablement convaincu le secrétaire général que l'Église ne représentait pas un danger pour son pouvoir. Alors que le régime était en situation de menace mortelle, elle avait manifesté sa loyauté et prêté main-forte au gouvernement. Pourtant, la reconnaissance n'était pas le critère qui motivait Stalin, surtout s'agissant de choix politiques d'importance majeure, comme c'était le cas de la politique religieuse.

La nécessité de donner des gages à l'opinion publique anglaise et américaine et la visite prochaine d'une délégation de l'Église anglicane prévue pour septembre 1943 portèrent le gouvernement soviétique à juger opportune une amélioration de la

de la maison du Seigneur : Le patriarche de Moscou et de toutes les Russies, Sergij (Stragorodskij). Le sacrifice pour rester dans la vérité de l'orthodoxie], M. : Pravilo very, 2003.

9. Sur les différentes lectures des motivations qui poussèrent Stalin à changer le cap de sa politique religieuse, cf. John Shelton Curtiss, The Russian Church and the Soviet State 19171950, Boston : Little, Brown, 1953, p. 300 ; Dmitrij V. Pospelovskij, Russkaja pravoslavnaja cerkov' $V X X$ veke [L'Église orthodoxe russe au $X X^{\mathrm{e}}$ siècle], M. : Respublika, 1995, p. 192-193 ; Vladislav Cypin, Istorija Russkoj Cerkvi 1917-1997 [Histoire de l'Église russe 1917-1997], M. : Izdatel'stvo Spaso-Preobraženskogo Valaamskogo monastyrja, 1997, p. 293-296 ; M.V. Škarovskij, Russkaja Pravoslavnaja Cerkov' pri Staline i Hruščëve (GosudarstvennoCerkovnye otnošenija v SSSR v 1939-1964 godah) [L'Église orthodoxe russe sous Stalin et Hruščëv (Les relations État-Église de 1939 à 1964)], M. : Krutickoe Patriaršee Podvor'eObščestvo ljubitelej cerkovnoj istorii, 1999, p. 202-204 ; O.Ju. Vasil'eva, Russkaja Pravoslavnaja Cerkov' v politike sovetskogo gosudarstva v 1943-1948 gg. [L'Église orthodoxe russe dans la politique de l'État soviétique au cours des années 1943-1948], M. : Institut rossijskoj istorii RAN, 1999, p. 105-127 ; A. Dickinson, «A Marriage of Convenience? Domestic and Foreign Policy Reasons for the 1943 Soviet Church-State "Concordat" », Religion, State \& Society, 28 (4), 2000, p. 337-346. 
condition de l'Église orthodoxe russe ${ }^{10}$. Néanmoins, afin de susciter chez les ecclésiastiques anglais une impression favorable sur la situation religieuse, il n'était certes pas indispensable de redessiner entièrement les contours des rapports entre l'État et l'Église, comme pourtant il s'appliqua à le faire. En outre, en septembre 1943, la situation militaire sur le front soviétique était telle que l'ouverture d'un second front n'était plus pour Moscou une nécessité vitale. Il n'était pas non plus indispensable d'accorder à l'Église des concessions importantes afin d'encourager son action patriotique, alors que, en 1941, celle-ci s'était produite spontanément, sans la moindre incitation. C'est plutôt dans le cadre des perspectives expansionnistes impériales et des horizons géopolitiques de l'après-guerre qu'il faut chercher les motivations premières du choix fait par Stalin à l'endroit de l'Église orthodoxe. L'amélioration de la situation militaire, après Stalingrad et Kursk, et la perspective, quoique lointaine, de la possibilité d'une victoire effective, changèrent l'ordre des priorités dans l'agenda politique des autorités soviétiques. En fait, ce fut au cours de ces mois-ci que Stalin, qui n'était plus obligé de se consacrer exclusivement à la lutte pour sauver son pays de l'agression nazie, commença à focaliser son attention sur les plans pour l'organisation du monde d'après-guerre et la défense des intérêts géopolitiques de Moscou $^{11}$.

C'est dans ce contexte que mûrit l'idée d'une implication de l'Église orthodoxe russe dans les desseins géopolitiques de l'État soviétique. Il est probable que ce fut là la motivation principale qui conduisit Stalin à imprimer à la politique religieuse le tournant de septembre $1943^{12}$. Le rôle que l'Église a pu jouer dans cette période du stalinisme était lié aux projets d'expansion territoriale de l'Union soviétique et d'élargissement de sa sphère d'influence.

L'avancement des frontières occidentales aurait impliqué, en Ukraine, en Biélorussie, en Bessarabie, en Bukovine et dans les pays Baltes, l'annexion définitive des régions où l'Église avait conservé presque intégralement son enracinement dans la société. Le Patriarcat de Moscou, comme cela s'était déjà produit en partie entre 1939 et 1941, pouvait exercer là une fonction de grande importance en neutralisant, ou du moins en atténuant, la teneur antirusse, et par conséquent antisoviétique, des sentiments religieux des populations frontalières. En ce sens, l'expérience tsariste offrait un précédent significatif. De fait, l'Église orthodoxe avait été manipulée plus d'une fois pour conforter le pouvoir de Moscou et contrecarrer l'action des confessions religieuses à tendance antimoscovite. Ce fut aussi le

10. Voir la lettre du commissaire à la sécurité d'État de l'URSS, V.N. Merkulov, à A.S. Ščerbakov, du 3 juillet 1943, soveršenno sekretno [top secret], in M.I. Odincov, Religioznye organizacii $v$ SSSR nakanune $i$ v gody velikoj otečestvennoj vojny 1941-1945 gg. [Les organisations religieuses en URSS à la veille et au cours des années de la Grande Guerre patriotique 1941-1945], M. : Izd-vo RAGS, 1995, p. 78-79.

11. Cf. Vojtech Mastny, The Cold War and Soviet Insecurity: The Stalin Years, Oxford-New York : Oxford University Press, 1996.

12. Voir aussi les observations de Steven Merritt Miner, Stalin's Holy War: Religion, Nationalism, and Alliance Politics, 1941-1945, Chapel Hill-Londres : The University of North Carolina Press, 2003. 
cas à la fin de la guerre avec la lutte contre les tendances indépendantistes du clergé sur des bases nationales présentes dans divers secteurs de l'orthodoxie ou avec le processus de liquidation de l'Église gréco-catholique en Ukraine occidentale ${ }^{13}$.

En outre, les plans pour transformer les pays d'Europe orientale et balkanique en une zone d'influence soviétique ne pouvaient pas ne pas prendre en compte le rôle joué par la religion chez les populations de ces régions. L'influence du clergé, le lien étroit entre appartenance confessionnelle et identité nationale, l'enracinement de l'Église dans les populations majoritairement rurales, poussèrent Stalin à prêter attention à la question religieuse dans les pays d'Europe orientale et à en tenir compte dans l'élaboration de la stratégie soviétique. Dans certains de ces États, en Bulgarie, Roumanie et en Yougoslavie, la tradition orthodoxe prévalait. Le Patriarcat de Moscou pouvait jouer pour les Églises de ces pays son rôle traditionnel de protection et de soutien aux intérêts de la politique extérieure soviétique ${ }^{14}$. Le pouvoir soviétique avait besoin pour sa projection internationale et son expansion impériale de disposer de l'appui de l'Église orthodoxe, dont la renaissance devait être favorisée dans le cadre d'une soumission à l'État.

\section{Le gouvernement et le patriarche}

La mise en œuvre de la nouvelle politique envers l'Église russe incombait en grande partie au SPDRPC, dont la présidence avait été confiée à Karpov. Qui était Georgij Grigor'evič Karpov? Sa carrière politique débute après la guerre civile ${ }^{15}$. En 1920, il devient membre du parti communiste et en 1922, il commence à travailler au sein de la GPU. En juillet 1937, il est nommé responsable du quatrième département « secret-politique » de Leningrad, qui avait entre autres missions celle de contrôler le clergé et les associations religieuses. Karpov fut donc un des responsables du NKVD à Leningrad pendant les mois de la Terreur. C'était, comme tant d'autres,

13. Dans l'abondante bibliographie sur la liquidation de l'Église gréco-catholique, voir Bohdan R. Bociurkiw, The Ukrainian Greek Catholic Church and the Soviet State (1939-1950), Edmonton-Toronto : Canadian Institute of Ukrainian Studies Press, 1996, p. 102-212 ; Likvidacija UHKC (1939-1946) : Dokumenty radjans 'kyh orhaniv deržavnoji bezpeky [La liquidation de L'Église gréco-catholique d'Ukraine (1939-1946). Documents des organes soviétiques de la sécurité d'État], Kyjiv : PP Serhijčuk M.I., 2006, 2 vol.

14. Sur la « stratégie religieuse » de l'Union soviétique dans l'après-guerre, se reporter à Andrea Riccardi, Il Vaticano e Mosca 1940-1990, Roma-Bari : Laterza, 1992 ; Tat'jana V. Volokitina, Galina P. Muraško, Al’bina F. Noskova, Moskva i Vostočnaja Evropa : Vlast'́ i cerkov' $v$ period obščestvennyh transformacij 40-50-h godov XX veka [Moscou et l'Europe orientale. Pouvoir et Église pendant la période de transformations sociales des années 1940-1950 du $X X^{\mathrm{e}}$ siècle], M. : Rosspen, 2008.

15. Les informations sur la biographie de Karpov, sauf mention explicite d'autres sources, sont tirées de Tat'jana A. Čumačenko, Gosudarstvo, pravoslavnaja cerkov', verujuščie. 19411961 gg. [État, Église orthodoxe, croyants, 1941-1961], M. : AIRO-XX, 1999, p. 98 note 1. L'auteur renvoie à la direction centrale des archives du FSB de la Fédération de Russie, probablement au dossier personnel de Karpov, sans toutefois préciser sa localisation. 
un fonctionnaire de la police politique, ayant voué obéissance à Stalin et fidélité au parti et à sa ligne politique.

En 1941, des fonctionnaires de la police politique du district de Pskov, qui dépendait directement de Karpov, furent condamnés pour leur activité dans les années 1937-1938, et le tribunal militaire de Leningrad intenta une procédure pénale à son encontre également. Cependant, au même moment, Karpov, probablement aussi grâce aux bons offices du nouveau chef du NKVD de Leningrad, Sergej A. Goglidze, fidèle collaborateur de Lavrentij P. Berija et ancien chef de la police politique de Géorgie, s'était déjà fait muter à Moscou, en qualité de chef de section à la direction centrale. Le procès fut donc classé sans suites. Pourtant, en 1956, le comité de contrôle du parti enquêta sur les activités de Karpov pendant les années de la Terreur. Les conclusions de l'enquête établirent qu'il «avait perpétré des arrestations de masse, employé des méthodes d'investigations perverses, falsifié des procès-verbaux d'interrogatoires $\gg^{16}$.

Arrivé à Moscou dans sa quarante-troisième année en février 1941, Karpov avait à son actif de longues années de service au sein du NKVD, au cours desquelles il avait fait montre, en plus sans doute de sa disposition à suivre sans ciller les ordres, de sa faculté à traverser indemne les épurations successives des années précédentes. En décembre 1941, il fut nommé responsable du quatrième département de la troisième section du NKVD, chargée de la « lutte contre la contrerévolution cléricale-sectaire », cette structure qui, depuis 1938, avait pour mission de contrôler l'Église orthodoxe. En février 1943, il fut nommé colonel et en mai, la direction du cinquième département de la deuxième section du NKGB, à peine institué, lui fut confiée. À ce titre il fut appelé par Stalin à diriger le nouvel organe gouvernemental : Karpov était un représentant sûr de l'institution la plus efficace du régime, et avait probablement aussi fait montre d'une compétence certaine à traiter les affaires ecclésiastiques ; tout cela garantissait qu'il allait mener à bien et sans faillir la tâche que Stalin voulait lui confier. Karpov, nommé general-major en juillet 1945, resta en fonction au sein des services de sécurité jusqu'en mars 1955 , continuant à occuper des postes à hautes responsabilités.

Parmi les compétences du SPDRPC, qui devait assumer la fonction de lien, de maillon entre l'Église et l'État, la prééminence avait été donnée au rapport direct avec les ecclésiastiques et au contrôle des activités de l'Église, plutôt qu'à un travail de vérification de la stricte application de la législation soviétique relative aux cultes en vigueur. Lors d'une réunion de formation des fonctionnaires du SPDRPC, Karpov insiste sur cet aspect prioritaire de leur travail : « des conversations avec l'évêque sont nécessaires, asseyez-vous, parlez avec lui, parlez avec les prêtres, parlez avec les laïcs ${ }^{17}$. Il s'agissait là d'un type de mission dont l'exécution

16. Sur ces questions, cf. Vadim Z. Rogovin, Partija rasstreljannyh [Le parti des fusillés], M. : s.n., 1997, p. 317-318, et Felix Corley, Religion in the Soviet Union: An Archival Reader, Londres : MacMillan Press, 1996, p. 203-204.

17. «Sténogramme du séminaire des délégués du Conseil pour les affaires de l'Église orthodoxe russe auprès du Conseil des commissaires du peuple de l'Ukraine », Kiev, 14 mai 1945, GARF, f. 6991, op. 1, d. 27, 1. 50 ob. 
requérait les méthodes de travail «personnalisées » d'un fonctionnaire des services de sécurité.

La contiguïté entre le NKGB et le SPDRPC porte à croire qu'il y eut coordination entre l'activité des deux organes dans le cadre d'une coopération devant appliquer la ligne unique de la politique religieuse. Dans son rapport au Comité central de mars 1955, Karpov déclarait avoir entretenu avec la section de la police politique chargée des affaires ecclésiastiques un « contact quotidien ${ }^{18}$. Pourtant, malgré cela, l'organisme présidé par Karpov ne fut pas une agence des services de sécurité. Il était certes difficile de défendre les frontières du domaine de compétences du SPDRPC contre l'empiétement des agents de la police politique, qui continuaient souvent, et ce en particulier à l'échelle locale, à gérer les relations avec les responsables des communautés religieuses, comme ils l'avaient d'ailleurs toujours fait. Il est significatif qu'en juillet 1945, Merkulov ait été conduit à envoyer une circulaire aux responsables du NKGB dans le but de réaffirmer la distinction des rôles entre les fonctionnaires du SPDRPC et les agents des services de sécurité ${ }^{19}$.

Malgré les difficultés, le SPDRPC acquit un profil original en dépit des multiples entraves qui limitaient l'autonomie de toute institution soviétique. Le 7 octobre 1943, un décret du Conseil des commissaires du peuple (SNK) approuva les statuts de la nouvelle institution comme organe du pouvoir exécutif. Elle était dotée d'un appareil central et d'un corps de délégués auprès des administrations des républiques de l'Union et des républiques autonomes, ainsi qu'auprès des comités exécutifs des oblasti et des $\mathrm{kraja}^{20}$. Le nouvel organisme naissait avec un statut pansoviétique et devint au cours des années restantes du stalinisme l'interlocuteur privilégié des autorités du pays pour ce qui concernait la politique envers l'Église orthodoxe. La première tâche que le décret assignait au SPDRPC était l'examen des questions soulevées par le patriarche. S'y ajoutaient l'élaboration d'actes législatifs et de délibérations sur les sujets liés à l'Église, le contrôle de la bonne application des normes gouvernementales sur le territoire soviétique, la présentation au gouvernement d'avis et d'informations relatives à la vie de l'Église, le décompte des églises et la collecte de données statistiques.

Les hauts responsables du SPDRPC (président, vice-président, et assistant du président) furent recrutés dans les fichiers des membres du NKGB. Il en fut de même pour les délégués dans les régions les plus sensibles politiquement, comme celles libérées de l'occupation allemande, pour lesquelles Molotov en personne conseilla de faire confiance au personnel de la police politique : « il faut, avait souligné Karpov, que dans les oblasti libérées, ce soient des tchéquistes qui soient

18. Lettre de G.G. Karpov au Comité central du PCUS, du 12 mars 1955, n. 189/s, sekretno [secret], GARF, f. 6991, op. 1, d. 1224, 1. 124.

19. La lettre de Merkulov du 7 juillet 1945 est publiée dans Likvidacija UHKC (1939-1946), vol. II, p. 16-19.

20. Le texte de l'ordonnance est publié dans Odincov, Religioznye organizacii v SSSR nakanune i v gody velikoj otečestvennoj vojny, p. 81-82. 
nommés délégués $»^{21}$. Le reste du personnel, tant au niveau central que régional, fut formé d'employés issus des structures de l'appareil d'État. Le processus de recrutement du corps des délégués se déroula lentement. En février 1944, on comptait 43 délégués en exercice, nombre qui ne s'éleva à 112 qu'à la fin de l'année 1946. Le recrutement des fonctionnaires capables d'appliquer au niveau local la nouvelle ligne de politique religieuse n'était pas chose facile. Il n'était pas rare que les comités du parti des oblasti attribuent les fonctions de délégués du SPDRPC à ceux qui par le passé s'étaient distingués dans la propagande antireligieuse et qui ne s'alignaient pas sur la nouvelle orientation des relations entre l'Église et l'État ${ }^{22}$. Le contrôle strict de l'activité des délégués par les instances centrales du SPDRPC et l'implication continue dans leur formation furent les méthodes mises en œuvre par Karpov pour animer avec succès un appareil efficace, comme l'a observé Tat'jana A. Čumačenko :

Il a réussi, en temps de guerre, à créer une structure complètement nouvelle au sein du système du pouvoir étatique ; il a forgé un appareil capable de remplir de façon opérationnelle et avec la compétence nécessaire les fonctions qui lui avaient été attribuées par les autorités du pays. ${ }^{23}$

Karpov transmettait des rapports à Molotov sur son propre travail et sur la situation de l'Église, et s'adressait directement à Stalin pour les questions d'importance majeure ; il recevait des deux dirigeants des indications quant aux décisions à appliquer $^{24}$. Cela témoignait clairement, de la part des plus hautes autorités soviétiques, de l'intérêt politique porté, à partir de 1943, à la politique religieuse et à l'Église orthodoxe. Karpov lui-même souligna cet aspect lors d'une rencontre avec des délégués du SPDRPC en 1945 : «Chaque jour, je peux régler telle ou telle question avec Vjačeslav Mihajlovič Molotov, qui s'occupe directement du Conseil $»^{25}$.

Lors de la fondation du SPDRPC, Stalin avait donné à Karpov des directives sur le mode opératoire du nouvel organe. Il ne devait prendre aucune initiative qui eût pu apparaître comme « une ingérence directe dans la vie administrative, canonique et dogmatique de l'Église ». Une autre règle de base était de «ne pas regarder dans le portefeuille (smotret' $v$ karman) de l'Église et du clergé » afin de ne pas

\section{Ibid., p. 84.}

22. Cf. Čumačenko, Gosudarstvo, pravoslavnaja cerkov', verujuščie, p. 23-45.

23. Ibid., p. 45.

24. Dans une remarque sur sa conversation avec Molotov, Karpov rapportait que celui-ci lui avait donné l'autorisation de référer à lui et à Stalin directement : cf. Volokitina, «Vlast' i pravoslavnye cerkvi v SSSR i stranah Vostočnoj Evropy (1944-1953 gg.) [Le pouvoir et les Églises orthodoxes en URSS et dans les pays d'Europe de l'Est (1944-1953)] », in Volokitina, Muraško, Noskova, éds., Moskva i Vostočnaja Evropa, p. 74.

25. «Sténogramme du séminaire des délégués du Conseil pour les affaires de l'Église orthodoxe russe auprès du Conseil des commissaires du peuple de l'Ukraine », Kiev, 14 mai 1945, GARF, f. 6991, op. 1, d. 27,1. 48. 
compromettre les relations entre le SPDRPC et les autorités ecclésiastiques ${ }^{26}$. L'objectif auquel il fallait tendre avant tout était d'établir de bonnes relations avec les hautes autorités de l'Église et avec l'épiscopat, en leur garantissant nécessairement l'exercice de leur propre pouvoir au sein des structures ecclésiastiques. Il importait en particulier que le président du SPDRPC accordât une attention spéciale au patriarche :

Le président du Conseil doit établir des relations telles avec le patriarche qu'elles ne puissent offrir au pouvoir ecclésiastique le prétexte de considérer le président du Conseil comme un ober-prokuror. En outre, il doit organiser des rencontres avec le patriarche, des dialogues, formes de contact adéquates qui peuvent être mises à profit pour exercer une influence avantageuse. ${ }^{27}$

L'organe exécutif de la politique religieuse avait aussi reçu formellement la mission de garantir la solidité du « lien entre le gouvernement de l'URSS et le patriarche de Moscou et de toutes les Russies sur les questions de l'Église russe orthodoxe qui requièrent une autorisation du gouvernement de 1 'URSS ${ }^{28}$. Il est significatif que la fonction spécifique du nouvel organisme d'État ait justement été le rapport direct avec le patriarche et non avec les structures ecclésiastiques dans leur ensemble.

D'un point de vue juridique, le Patriarcat n'avait pas de personnalité propre, et la législation reconnaissait uniquement l'existence des associations religieuses, c'est-à-dire des paroisses. Il s'agissait d'un revirement de la politique menée dans les années 1920 et 1930, quand l'un des principaux objectifs des autorités soviétiques avait été de favoriser l'apparition de scissions au sein de l'Église, pour affaiblir la direction ecclésiastique jusqu'à la désagrégation ${ }^{29}$. Au contraire, c'est le

26. Voir la note sur les directives reçues à l'occasion de l'organisation du Conseil, sekretno [secret], ainsi que la lettre de G.G. Karpov au Comité central du PCUS du 6 mai 1954, n. 339/s, RGANI (Rossijskij Gosudarstvennyj Arhiv Novejšej Istorii - Archives russes d'État d'histoire contemporaine), f. 5, Apparat CK KPSS (1949-1991), op. 16, Otdel propagandy i agitacii, r. 5580, d. 669, 1. 4-5.

27. Ibid., 1. 4 .

28. Odincov, Religioznye organizacii $v$ SSSR nakanune i v gody velikoj otečestvennoj vojny, p. 81 .

29. Sur la politique religieuse des bolcheviks et sur les scissions internes au sein de l'Église orthodoxe russe dans les années 1920, en sus des pages consacrées aux travaux déjà cités de Pospelovskij et Cypin, voir : Aarto Luukkanen, The Party of Unbelief: The Religious Policy of the Bolshevik Party, 1917-1929, Helsinki : SHS, 1994 ; M.I. Odincov, Gosudarstvo i Cerkov' $v$ Rossii. XX vek [L'État et l'Église en Russie au XX ${ }^{\mathrm{e}}$ siècle], M. : Luč, 1994,p. 47-90 ; N.A. Krivova, Vlast' i Cerkov'v 1922-1925 gg. : Politbjuro i GPU v bor'be za cerkovnye cennosti i političeskoe podčinenie duhovenstva [Pouvoir et Église 1922-1925 : Le Politbjuro et la GPU dans la lutte pour les biens de l'Église et la soumission politique du clergé], M. : AIRO-XX, 1997 ; Anatolij N. Kaševarov, Pravoslavnaja Rossijskaja Cerkov' i sovetskoe gosudarstvo (19171922) [L'Église orthodoxe russe et l'État soviétique (1917-1922)], M. : Izdatel'stvo Krutickogo Podvor'ja-Obščestvo ljubitelej cerkovnoj istorii, 2005. Un recueil d'intérêt fondamental a été compilé dans Nikolaj N. Pokrovskij, Stanislav G. Petrov, éds., Arhivy Kremlja : Politbjuro $i$ Cerkov' 1922-1925 gg. [Les archives du Kremlin : Le Politbjuro et l'Église, 1922-1925], 2 vol., Novosibirsk-M. : Sibirskij hronograf-Rosspen, 1997-1998. Sur le schisme des « rénovateurs », voir entre autres Catherine Gousseff, « Le schisme rénovateur : un mouvement pro-commu- 
soutien aux autorités ecclésiastiques qui prévalait à présent, et tout particulièrement au patriarche. La reconnaissance par l'État de la direction ecclésiastique avait été l'objectif poursuivi sans relâche par Sergij, et l'infatigable défense de sa survie le moteur principal de la ligne d'action tenue par le locum tenens. Il ne s'agissait pourtant pas que d'un accueil bienveillant ou intéressé aux aspirations de l'Église. En fait, l'importance donnée aux relations avec le patriarche et avec les évêques et le renoncement à la politique qui favorisait les processus de démantèlement ou la poursuite de la liquidation des autorités ecclésiastiques ne furent pas des choix conjoncturels dictés par opportunisme tactique, mais constituèrent une constante de la politique religieuse soviétique à partir de 1943, même dans les phases de tension majeure. L'expérience des décennies précédentes avait probablement convaincu les autorités soviétiques de l'opportunité d'une structure centralisée de l'Église, qui en permît un contrôle plus aisé.

Les « Normes sur l'administration de l'Église russe orthodoxe », approuvées par le concile de l'Église russe du 31 janvier 1945, après ratification préalable par le SNK, sanctionnèrent la centralisation du système administratif de l'Église. Elles « fixaient un ordre hiérarchique rigide de l'administration ecclésiastique, accroissant les pouvoirs du patriarche, des évêques éparques et des paroisses $»^{30}$. La direction

niste dans l'Église orthodoxe russe », Revue d'Études comparatives Est-Ouest, 24 (3-4), 1993, p. 9-28 ; D.V. Pospelovskij, « The Renovationist Movement in the Orthodox Church in the Light of Archival Documents », Journal of Church and State, 39 (1), 1997, p. 85-105 ; Il'ja V.Solov’ëv, éd., «Obnovlenčeskij » raskol (Materialy dlja cerkovno-istoričeskoj i kanoničeskoj harakteristiki) [Le schisme du « renouveau » (Matériaux pour une description historico-ecclésiastique et canonique)], M. : Izdatel'stvo Krutickogo Podvor' ja-Obščestvo ljubitelej cerkovnoj istorii, 2002 ; Edward E. Roslof, Red Priests: Renovationism, Russian Orthodoxy, and Revolution, 1905-1946, Bloomington-Indianapolis : Indiana University Press, 2002. Sur le mouvement $\mathrm{du}$ « renouveau », les travaux de Anatolij Levitin-Krasnov et Vadim Šavrov, Očerki po istorii russkoj cerkovnoj smuty [Essais sur l'Histoire de la révolte ecclésiastique russe] gardent à ce

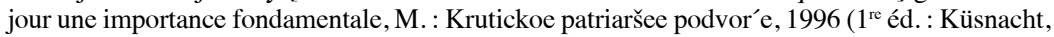
Suisse : Institut Glaube in der 2. Welt, 1978). Sur les différents schismes après la mort de Tihon et la régence du métropolite Sergij, voir : Lev Regel'son, Tragedija Russkoj Cerkvi 1917-1945 [La tragédie de l'Église orthodoxe russe, 1917-1945], postface de Ioann Mejendorf, P. : YmcaPress, 1977 ; D.V. Pospelovskij, « Mitropolit Sergij i raskoly sprava [Le métropolite Sergij et les schismes de droite] », Vestnik russkogo hristianskogo Dviženija, n 158, 1990, p. 53-81; Ioann (Snyčev), Cerkovnye raskoly v Russkoj cerkvi 20-h i 30-h godov xx stoletija - Grigorianskij, Jaroslavskij, Iosifljanskij, Viktorianskij i drugie, ih osobennosti i istorija [Les schismes au sein de l'Église orthodoxe russe dans les années 1920-1930: grégoriens, joséphins, victoriens, de Jaroslavl', et autres : histoire et particularités], $2^{\mathrm{e} e ́ d . ~ a u g m e n t e ́ e, ~ S o r t a v a l a ~: ~ I z d a t e l ' s t v o ~ S o r t a-~}$ valskoj knižnoj tipografii, 1993 ; M.V. Škarovskij, Iosifljanstvo : tečenie v Russkoj Pravoslavnoj Cerkvi [Le mouvement joséphin : un courant de l'Église orthodoxe russe], SPb. : NIC « Memorial », 1999; Aleksandr V. Žuravskij, « K voprosu o klassifikacii oppozicionnyh dviženij i grupp mitropolitu Sergiju (Stragorodskomu) [De la classification des mouvements et des groupes d'opposition au métropolite Sergij (Stragorodskij)] », in Istorija Russkoj Pravoslavnoj Cerkvi V XX veke (1917-1933 gg.) [L'Histoire de l'Église orthodoxe russe au XX $X^{\mathrm{e}}$ siècle (1917-1933)], Actes du congrès de Szentendre (Hongrie), 13-16 novembre 2001, vol. I, Munich : Izdanie Obiteli Prep. Iova Počaevskogo, 2002, p. 349-383. En ce qui concerne les divisions internes au sein de l'Église en Ukraine, on se rapportera au travail de Simona Merlo, All'ombra delle cupole d'oro : La Chiesa di Kiev da Nicola II a Stalin (1905-1939), préface de Roberto Morozzo della Rocca, Milan : Guerini e Associati, 2005, p. 241-370.

30. Cypin, Istorija Russkoj Cerkvi 1917-1997, p. 324. Voir aussi Nikita Struve, Les Chrétiens en URSS, P. : Seuil, 1963, p. 72-74. Pour les délibérations conciliaires sur les « Normes », cf. «Istoričeskie dni [Journées historiques] », Žurnal Moskovskoj Patriarhii, n 2, 1945, 
de l'Église était confiée au patriarche et à un saint-synode composé d'évêques, alors que n'était pas prévue l'existence d'un conseil suprême de l'Église composé aussi de moines, de prêtres et de laïcs, tel qu'il avait été adjoint au synode par le concile de 1917-1918 ${ }^{31}$. Les « Normes » établissaient aussi que le synode serait constitué, en plus du patriarche, de trois membres permanents, les métropolites de Kiev, de Leningrad et de Kruticy, ainsi que de trois membres choisis alternativement chaque semestre parmi les autres évêques. De la nouvelle structure émergeait une élite de l'épiscopat, composée de trois membres permanents qui, avec le patriarche, disposaient de la majorité des votes au synode. Le gouvernement de l'Église fut, de fait, confiée à ces plus hautes autorités de l'épiscopat.

D'après le nouveau règlement, l'évêque était subordonné au concile, au patriarche et au synode. L'ordinaire était libre de gouverner son éparchie même sans le seul organe collégial prévu par les « Normes », le conseil éparchial, dont la composition ne prévoyait pourtant pas la participation de laïcs contrairement à ce qui avait été établi par le concile de 1917-1918. L'épiscopat reprenait également en main le contrôle des paroisses, à travers le recteur, nommé par l'ordinaire, responsable envers lui et placé à la tête de la communauté paroissiale, et de son organe exécutif dont il était président de droit. Cette dernière mesure allait à l'encontre de l'ordonnance d'État du 9 avril 1929 sur les associations religieuses, selon laquelle les prêtres n'étaient autres que des salariés pris en charge par la communautée ${ }^{32}$. Karpov, présentant le texte des « Normes » à Molotov, ne manqua pas de relever cette contradiction, mais se dit favorable au changement relatif à la direction des paroisses proposé par le Patriarcat de $\mathrm{Moscou}^{33}$. Pourtant, la législation sur les associations religieuses ne fut pas modifiée, ce qui laissait ainsi au gouvernement la liberté, s'il le jugeait opportun, d'utiliser cette discordance pour contraindre l'Église à modifier les dispositions sur l'administration des paroisses, afin de la restituer aux communautés paroissiales, comme ce serait le cas en 1961.

Le SPDRPC avait donc entériné le remaniement des structures ecclésiastiques proposées par le Patriarcat, qui rétablissait une organisation verticale rigide

p. 31-85, en particulier p. 42-46. Pour la ratification du texte par le SNK, voir le décret n. 162 du 28 janvier 1945 relatif aux « Normes sur le gouvernement de l'Église orthodoxe russe » qui contient le texte des dites « Normes », GARF, f. 6991, op. 2, Sovet po delam russkoj pravoslavnoj cerkvi pri Sovete Ministrov SSSR, d. 29, 1. 2-10.

31. Sur le concile de l'Église orthodoxe russe de 1917-1918, voir, dans l'ample bibliographie : Günther Schulz, Das Landeskonzil der Orthodoxen Kirche in Rußland 1917/18 - ein unbekanntes Reformpotential, Göttingen : Vandenhoeck \& Ruprecht, 1995 ; Adalberto Mainardi, éd., Il concilio di Mosca del 1917-1918, Actes du XI ${ }^{\mathrm{e}}$ Congrès œcuménique international de spiritualité orthodoxe, section russe, Bose, 18-20 septembre 2003, Magnano (BI) : Edizioni Qiqajon, 2004 ; Hyacinthe Destivelle, Le concile de Moscou (1917-1918) : La création des institutions conciliaires de l'Église orthodoxe russe, P. : Les Éditions du Cerf, 2006.

32. Le texte de l'ordonnance de 1929 est rapporté dans O.Ju. Vasil'eva, éd., Russkaja Pravoslavnaja Cerkov'i kommunističeskoe gosudarstvo. 1917-1941. Dokumenty i fotomaterialy [L'Église orthodoxe russe et l'État communiste, 1917-1941. Documents et matériaux photographiques], M. : Izdatel’stvo Biblejsko-Bogoslovskogo Instituta sv. apostola Andreja, 1996, p. 250-261.

33. Cf. la lettre de G.G. Karpov à V.M. Molotov du 10 janvier 1945, sekretno [secret], GARF, f. 6991, op. 1, d. 29, 1. 11-11ob. 
de la direction de l'Église. D'autre part, parmi les directives reçues par Karpov au moment de la fondation du SPDRPC, figurait la garantie des conditions dans lesquelles les évêques pouvaient être «patrons absolus» de leur éparchie ${ }^{34}$. Une fusion entre des exigences totalement distinctes, sinon opposées, s'était produite : celles des autorités ecclésiastiques et celles des autorités soviétiques. Toutes deux, de façon différente et avec des intérêts divergents voire contraires, favorisèrent le processus de centralisation des structures ecclésiastiques et de renforcement du pouvoir épiscopal qui marquerait profondément la face de l'Église russe dans la seconde moitié $\mathrm{du} \mathrm{xx}^{\mathrm{e}}$ siècle. Le rôle et le pouvoir du patriarche et des évêques en sortirent renforcés et l'épiscopat acquit une dimension centrale, par certains aspects inhabituelle, dans la vie de l'orthodoxie russe. L'appauvrissement de la vie ecclésiale consécutif aux persécutions rend cet aspect encore plus manifeste. Un épiscopat traditionnellement inséré dans une trame ecclésiale riche et complexe se trouva devoir soutenir la tâche malaisée de gouverner l'Église sous le stalinisme, sans l'appui des énergies les meilleures de l'orthodoxie russe décimée par les persécutions. Le patriarche, en premier, et les évêques à sa suite, furent projetés dans une situation d'extrême exposition dans la difficile mission de représentants, souvent isolés, de l'Église. Il fallait évoluer en terrain extraordinairement glissant à la recherche d'un équilibre entre contrôle de l'État, inévitables compromis et défense des intérêts de l'Église. Ainsi, le renforcement du pouvoir de l'épiscopat était incontestable mais son affaiblissement se profilait aussi. Le fait, entre autres, que l'épiscopat relevât d'une structure régie par des principes hiérarchiques rigides le plaçait en position de soumission par rapport au patriarche et au synode, ce qui ne manquait pas de contribuer à l'altération de son pouvoir.

\section{Un épiscopat courtisé et contrôlé}

L'épiscopat constituait l'objet principal de l'attention de Karpov et de ses hommes. Le contrôle du SPDRPC sur la vie de l'Église s'exerçait par le biais des relations avec les évêques. Les entrevues étaient l'outil privilégié dont les fonctionnaires usaient pour entretenir avec les prélats des relations fondées sur une attitude courtoise et attentionnée mais sans ambiguïté aucune sur les rôles et la prééminence des institutions d'État. S'adressant aux délégués du SPDRPC lors de leur première réunion à Moscou en 1944, Karpov entendait leur donner les rudiments nécessaires pour mener au mieux leur tâche. Il décrivait ainsi la forme que devaient prendre les relations avec le clergé :

Certains délégués n'ont pas trouvé la forme adéquate pour traiter avec les membres du clergé : ils entretiennent une correspondance de service, ils s'adressent à eux en recourant à leurs titres ecclésiastiques. Il ne doit pas être

34. « Note sur les directives reçues à l'occasion de l'organisation du Conseil », sekretno [secret], à laquelle il faut ajouter la lettre de G.G. Karpov au Comité central du PCUS, du 6 mai 1954, n. 339/s, RGANI, f. 5, op. 16, r. 5580, d. 669, 1. 4. 
tenu de correspondance, toutes les questions doivent être résolues de vive voix, pendant les heures de réception au bureau. Il faut s'adresser à eux en les appelant par leur nom et patronyme $»^{35}$.

L'objectif des relations avec les évêques était de garantir une collaboration satisfaisante avec les autorités ecclésiastiques, condition nécessaire à la réalisation efficace des missions du SPDRPC. À l'occasion de la conférence des délégués ukrainiens en mai 1945, Karpov décrit ainsi sa philosophie des rapports aux évêques :

À présent vous avez devant vous un grand travail : aider les évêques et les archevêques à se conformer aux nouvelles normes de l'administration de l'Église orthodoxe russe. Vous ne devez pas les entraver, mais les aider [...]. Bien sûr, si l'évêque fait valoir ses droits de façon illégale, vous devez régler la question avec lui par le dialogue, mais pour tout le reste, si ne transparaît de son côté aucune duplicité, aidez-le [...]. Avec le clergé, quel qu'il soit, de quelque grade qu'il soit, et avant tout avec les évêques, il vous faut entretenir des relations normales. Vous devez comprendre que beaucoup de choses dépendent de vos relations personnelles. Vous ne devez pas avoir de confiance excessive, sans pour autant adopter une attitude méprisante ou grossière à l'égard du clergé. [...] Par exemple, à Tambov, je me suis rendu chez le délégué et lui ai dit «Quand tu convoqueras l'évêque, je viendrai moi aussi ». Imaginez ce que j'ai pu ressentir à mon arrivée : le délégué fumait. [...] il fumait tout en parlant avec l'évêque. C'est scandaleux. Mais le délégué ne comprend pas que de telles choses ne se font pas. Même si c'est un évêque qu'on reçoit, c'est un moine, non seulement il ne fume pas mais il ne supporte pas cela. En plus, dans l'absolu, ce n'est pas beau. [...] Je connais tout l'épiscopat, parce que tous les évêques sont venus me voir, je les ai tous reçus collectivement et individuellement. Je sais qu'il y en a des bons et qu'il y en a des mauvais. Je vous demande de prendre tout cela en compte parce que leur façon de penser dépendra de vous. ${ }^{36}$

Soumettre abruptement les ecclésiastiques aux volontés des fonctionnaires n'était pas le meilleur moyen d'atteindre les objectifs de la politique religieuse de Stalin. L'attention que portait le SPDRPC aux relations avec l'épiscopat avait pour but de contrôler de façon plus efficace la vie de l'Église et de l'orienter avec les plus grandes chances de succès possible dans un sens correspondant aux intérêts de l'État. Karpov, sans doute aussi pour tenter de faire ressortir l'importance et l'efficacité de son travail, soulignait cet aspect dans les comptes rendus qu'il envoyait aux autorités politiques du pays : «L'instauration de telles relations avec les hautes autorités ecclésiastiques permet au Conseil d'exercer une influence sur l'Église dans la direction nécessaire ${ }^{37}$. Selon lui, l'Église, elle aussi, était satisfaite de ces relations. Les conclusions que tiraient Karpov péchaient probable-

35. Citation extraite de l'intervention de G.G. Karpov à la conférence des délégués du Conseil pour les affaires de l'Église orthodoxe russe de 1944, GARF, f. 6991, op. 1, d. 6, 1. 31.

36. «Compte rendu sténographique de la conférence républicaine des délégués pour les affaires de l'Église orthodoxe russe auprès du SNK de la République socialiste soviétique ukrainienne », Kiev, 14 mai 1945, tol'ko dlja služebnogo pol'zovanija [à l'usage exclusif du service], GARF, f. 6991 , op. 1, d. 27, 1. 49ob-50.

37. Čumačenko, Gosudarstvo, pravoslavnaja cerkov', verujuščie, p. 59. 
ment par généralisation abusive. Pourtant, cette même méthode, celle des rapports personnels, employée par le président du SPDRPC, ne générait pas, en tant que telle, que des effets unilatéraux. Dans une certaine mesure, cela créait quelque complicité entre les deux protagonistes. À travers ce canal, les évêques pouvaient également faire entendre leur voix là où ils le voulaient et tenter de trouver en leur interlocuteur un défenseur de leurs intérêts auprès des autres instances du pouvoir soviétique. Évidemment, une telle synergie ne se produisait ni avec tous, ni sur tous les sujets.

Les relations entre épiscopat et fonctionnaires du SPDRPC n'étaient pas fondées sur une égalité de droits ni de possibilités d'agir. Au contraire, le rapport de forces était complètement déséquilibré. Le risque que l'État renonce unilatéralement au nouveau cours des rapports avec l'Église et revienne aux anciennes méthodes était loin d'être nul et le souvenir encore frais des persécutions subies le rappelait aux ecclésiastiques avec une particulière acuité. D'après les données collectées par les collaborateurs du SPDRPC, dans un document non daté mais remontant probablement à 1948, sur soixante-quatorze évêques recensés alors, trente-six avaient connu une condamnation, soit quasiment la moitié ${ }^{38}$. Que le SPDRPC mène la danse faisait partie des règles du jeu, tout comme son possible recours à d'autres armes, notamment la coercition, à laquelle l'Église ne pouvait guère s'opposer. Le fait même du double rôle de Karpov, que n'ignoraient vraisemblablement pas les autorités ecclésiastiques, illustrait la possibilité de recours à d'autres moyens pour les hommes du SPDRPC. Malgré cela, le choix par Stalin d'imposer que les relations avec l'Église reposent sur les bases de la collaboration, même limitée et soumise à instrumentalisation par le pouvoir politique, devait nécessairement passer par des compromis réciproques, quoique d'ampleur inégale.

De telles relations avec l'État offraient à l'Église un cadre institutionnel de relative stabilité que l'épiscopat était loin de dédaigner, après l'expérience des multiples «tournants » de la politique stalinienne dans les années 1930 qui l'avaient si dramatiquement atteinte ${ }^{39}$. L'Église était reconnue en tant qu'interlocuteur, même soumis, et avait à sa disposition un canal institutionnel, certes au demeurant discrétionnaire, à travers lequel communiquer ses exigences et être en partie écoutée. Tout cela, comparé avec ce qui s'était passé dans les décennies précédentes, pouvait effectivement satisfaire les responsables du Patriarcat. Leurs objectifs n'étaient pas les mêmes que ceux du SPDRPC. Bien que les autorités ecclésiastiques eussent pleine conscience de l'instrumentalisation de l'Église par le gouvernement, n'en

38. «Liste de l'épiscopat du patriarcat de Moscou », GARF, f. 6991, op. 2, d. 76, 1. 19-28.

39. Sur la politique religieuse dans les années 1930, en sus des travaux déjà cités sur l'histoire de l'Église russe dans la période soviétique, voir Valerij A. Alekseev, Illjuzii i dogmy [Illusions et dogmes], M. : Politizdat, 1991 ; Id., Sturm nebes otmenjaetsja ? Kritičeskie očerki po istorii bor'by s religiej v SSSR [L'assaut des cieux révoqué ? Essais critiques sur l'Histoire de la lutte contre la religion en URSS], M. : Rossija molodaja, 1992 ; Nicolas Werth, « Le pouvoir soviétique et l'Église orthodoxe de la collectivisation à la Constitution de 1936 », Revue d'Études comparatives Est-Ouest, 24 (3-4), 1993, p. 41-59 ; A. Luukkanen, The Religious Policy of the Stalinist State. A Case Study: The Central Standing Commission on Religious Questions, 1929-1938, Helsinki : SHS, 1997. 
prévalait pas moins le constat que la nouvelle situation leur ouvrait des marges de manœuvre pour la défense des intérêts de l'Église. La seule alternative concevable était d'envisager un retour aux formes de répression du passé récent. La crainte d'une reprise des persécutions et le désir de ne pas altérer le statu quo des relations entre Église et État poussèrent le patriarche à modérer les évêques et les ecclésiastiques les plus intransigeants dans l'affirmation sempiternelle et inconditionnelle des droits de l'Église et à les rappeler à la prudence dans l'exercice de leur ministère ${ }^{40}$.

\section{Réveil religieux}

La rencontre de Stalin avec les métropolites et l'élection de Sergij au patriarcat avaient été un signal encourageant pour les croyants qui, avec moins de crainte qu'auparavant, s'adressaient aux autorités pour réclamer que les églises mises sous séquestre soient restituées au culte. Le 28 novembre 1943, une délibération du gouvernement, inspirée d'une proposition de Karpov, établit la procédure à suivre pour juger de la recevabilité des demandes d'ouverture d'église. Deux niveaux d'examen étaient prévus : local et central ${ }^{41}$. Le but poursuivi était le contrôle centralisé de la politique religieuse sur l'ensemble du territoire de l'Union. Moscou tenait à se réserver la prérogative de décider du nombre et de la répartition géographique des églises dont la réouverture serait jugée opportune. Pourtant le droit de veto attribué en première instance aux organes locaux leur donnait une marge discrétionnaire relativement large, sur laquelle le SPDRPC avait peu de possibilité d'interférer.

Au mois d'octobre 1944, Karpov adressa à Molotov un rapport circonstancié sur la situation des églises orthodoxes dans le pays ${ }^{42}$. D'après les données du SPDRPC, au $1^{\text {er }}$ août, 8809 églises orthodoxes étaient ouvertes au culte dans l'ensemble du territoire de l'URSS, sans compter celles des trois Républiques baltes. Le président du SPDRPC pointait le nombre élevé d'édifices cultuels consacrés dans les territoires libérés de l'occupation des Allemands et de leurs alliés : environ 6 500, soit $73,7 \%$ du total, dont la majorité située en Ukraine.

40. Le cas le plus significatif est celui de la relation entre Aleksij et l'archevêque Luka (VojnoJaseneckij), figure à propos de laquelle on verra : Mark A. Popovskij, Žizn' i žitie svjatitelja Luki Vojno-Jaseneckogo arhiepiskopa i hirurga [ Vie et biographie du saint évêque Luka VojnoJaseneckij archevêque et chirurgien], P. : Ymca-Press, 1979 ; Vasilij Maruščak, Svjatitel'hirurg : žitie arhiepiskopa Luki (Vojno-Jaseneckogo) [Le saint évêque-chirurgien : Biographie

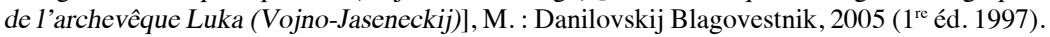

41. Voir Čumačenko, Gosudarstvo, pravoslavnaja cerkov', verujuščie, p. 67-68.

42. Rapport de G.G. Karpov à V.M. Molotov du 5 octobre 1944, soveršenno sekretno [top secret], GARF, f. 6991, op. 1, d. 3, 1. 215-222. 
Nombre d'églises par république ouvertes au culte en Union soviétique au $1^{\text {er }}$ août 1944

\begin{tabular}{|l|c|}
\hline \multicolumn{1}{|c|}{ Républiques } & Nombre d'églises ouvertes au culte \\
\hline Ukraine & 5206 \\
\hline RSFSR & 1907 \\
\hline Moldavie & 1100 \\
\hline Biélorussie & 550 \\
\hline Autres républiques & 46 \\
\hline URSS (républiques baltes exceptées) & 8809 \\
\hline
\end{tabular}

Source : rapport de G.G. Karpov à V.M. Molotov du 5 octobre 1944, soveršenno sekretno [top secret], GARF, f. 6991, op. 1, d. 3,1.215.

En revanche, concernant les zones qui n'avaient pas été soumises au contrôle allemand, la situation de la distribution des églises actives présentait des déséquilibres notables. Face à l'oblast' de Moscou, où étaient enregistrés 187 lieux de culte, et à celle de Jaroslavl', qui en comptait 162, le rapport recensait quatre unités administratives territoriales avec quatre églises, quatre autres qui en comportaient deux, et au moins six dotées d'une seule. Karpov ne manqua pas de signaler que, dans les oblasti où se trouvait une quantité non négligeable d'églises ouvertes au culte, il y avait aussi des zones qui en étaient entièrement dépourvues : ainsi 23 districts dans l'oblast de Moscou n'avaient pas d'église, 16 dans celle de Jaroslavl' et 39 dans celle de Orël ${ }^{43}$.

\section{Nombre d'églises ouvertes au culte dans certaines régions d'Ukraine et de RSFRS au $1^{\text {er }}$ août 1944}

\begin{tabular}{|l|l|}
\hline \multicolumn{1}{|c|}{$\begin{array}{c}\text { Régions } \\
\text { (en gras les régions ayant subi l'occupation allemande) }\end{array}$} & $\begin{array}{c}\text { Nombre d'églises ouvertes } \\
\text { au culte }\end{array}$ \\
\hline UKRAINE & \\
\hline Odessa & 500 \\
\hline Vinnica & 400 \\
\hline Kiev & 370 \\
\hline Černigov & 370 \\
\hline Žitomir & 300 \\
\hline Poltava & 258 \\
\hline Rovno & 258 \\
\hline Stalino & 222 \\
\hline Har'kov & 155 \\
\hline
\end{tabular}




\begin{tabular}{|c|c|}
\hline RSFSR & \\
\hline Kursk & 283 \\
\hline Krasnodar & 229 \\
\hline Moscou & 187 \\
\hline Jaroslavl' & 162 \\
\hline Rostov-na-Donu & 149 \\
\hline Stavropol' & 127 \\
\hline Orël & 108 \\
\hline Kalinin & 81 \\
\hline Voronež & 80 \\
\hline Smolensk & 60 \\
\hline Crimée & 60 \\
\hline Ivanovo & 58 \\
\hline Molotov & 32 \\
\hline Sverdlovsk & 28 \\
\hline Kirov & 24 \\
\hline Gor'kij & 21 \\
\hline Rjazan' & 16 \\
\hline Kujbyšev & 4 \\
\hline Saratov & 4 \\
\hline Tambov & 4 \\
\hline Čkalov & 4 \\
\hline Novosibirsk & 2 \\
\hline Penza & 2 \\
\hline Altaj & 2 \\
\hline Primor'e & 2 \\
\hline Irkutsk & 1 \\
\hline Kurgan & 1 \\
\hline Krasnojarsk & 1 \\
\hline Habarovsk & 1 \\
\hline République autonome des Mari & 1 \\
\hline République autonome de Mordovie & 1 \\
\hline
\end{tabular}

Source : rapport de G.G. Karpov à V.M. Molotov du 5 octobre 1944, soveršenno sekretno [top secret], GARF, f. 6991, op. 1, d. 3,1.215-216. 
Karpov attirait l'attention de Molotov sur la très grande quantité de demandes de réouverture d'églises présentées par les fidèles. Pas moins de 3045 étaient parvenues au cours du premier semestre. Les demandes provenaient en grande partie des oblasti centrales de la RSFSR, plus rarement des régions de l'Oural et de la Sibérie où il n'y avait que peu d'églises consacrées ${ }^{44}$. Les conclusions de Karpov étaient univoques : « il faut admettre que les pétitions sont massives et insistantes ». Ce phénomène réveillait chez le fonctionnaire soviétique des inquiétudes qu'il ne dissimulait pas :

La présence d'églises consacrées ainsi que l'ouverture de nouvelles églises donnent un élan certain au réveil de la vie ecclésiale. Il faut noter le rôle important joué par les moines sans charge (gyrovagues) dans l'accroissement du flux de pétitions de fidèles réclamant l'ouverture d'églises, mais aussi par d'anciens chefs de conseils paroissiaux, d'ex-trésoriers et autres activistes de l'Église intéressés par la perspective de rémunération dans l'église qui s'ouvrirait. ${ }^{45}$

La contention du nombre d'églises rouvertes était de toute façon assurée par la lenteur de traitement des demandes et la proportion élevée de pétitions rejetées. Les 3045 demandes parvenues en 1944 n'avaient été que partiellement examinées : sur les 1432 demandes qui avaient obtenu une réponse, 1280 avaient essuyé un refus de la part des autorités locales. Pourtant, les fidèles étaient déterminés à obtenir gain de cause :

Les groupes de croyants - rapportait Karpov - cherchent instamment à ce que leur demande obtienne satisfaction. Ils écrivent de façon répétée d'autres pétitions au gouvernement, au Conseil, aux organes soviétiques locaux, au synode et au Patriarcat ; souvent ils envoient leurs émissaires ou leurs délégations dans les chefslieux des oblasti ou des républiques ainsi qu'à Moscou. ${ }^{46}$

Le rapport indiquait que dans certains cas, les pétitions étaient assorties d'un millier de signatures. En général les signataires des pétitions déclaraient prendre en charge tous les frais nécessaires à la restauration des bâtiments, et, dans certaines régions où il ne restait plus d'édifices religieux, les fidèles présentaient des demandes pour l'obtention d'un permis de construire de nouvelles églises à leurs frais. C'était le cadre d'un réveil religieux, diffus dans le pays mais enraciné au cœur de la population. La réponse du gouvernement ne pouvait pas consister en un simple refus. Le phénomène risquait de se propager le long des réseaux de la vie ecclésiale clandestine, du «fanatisme religieux » animé par les «prêtres gyrovagues » appartenant

44. Les oblasti d'où étaient parvenues le plus grand nombre de pétitions étaient : Ivanovo (306), Moscou (241), Gor'kij (190), Tula (147), Kalinin (140), Voronež (137), Kirov (132), Rjazan' (127), Jaroslavl' (122).

45. Rapport de G.G. Karpov à V.M. Molotov du 5 octobre 1944, 1. 218.

46. Ibid., 1. 219. 
aux groupes orthodoxes les plus intransigeants ou des sectes avec leur part inévitable d'antisoviétisme radical. La ligne proposée par Karpov, et approuvée par Molotov, allait dans le sens du contrôle et de la contention de l'accroissement du nombre d'églises consacrées dans le pays.

L'ouverture des églises se fit donc dans des limites modestes, certes significatives non tant dans l'absolu que par rapport à la politique religieuse traditionnellement suivie par les bolcheviks. Si l'on considère le nombre d'édifices religieux désaffectés recensés par le SPDRPC (15 447 d'après des données incomplètes, dont 14585 dans la seule RSFSR), on peut soutenir que les autorités soviétiques auraient pu concéder l'ouverture d'un nombre d'églises bien supérieur, sans devoir destiner au culte des édifices voués à d'autres usages ${ }^{47}$. Pourtant, il faut noter que même dans la relative normalisation des rapports entre Église et État après septembre 1943, les autorités soviétiques n'avaient aucunement l'intention de tolérer un processus massif et spontané de réouverture des églises, comme celui qu'avaient connu les territoires occupés par les Allemands, ni de permettre une reprise de la vie ecclésiale au point de redonner aux structures ecclésiastiques la visibilité, l'enracinement et l'influence dans la société russe qui avaient été les leurs avant la révolution ou dans les premières années du gouvernement bolchevik. Il s'agissait d'une renaissance qui devait se dérouler dans le cadre d'un système politique fondé sur l'idéologie marxiste-léniniste. Les dirigeants bolcheviks ne pouvaient tolérer le renforcement d'une institution représentant potentiellement une alternative à leur pouvoir sur la société. Les fondements idéologiques du régime et tous ses postulats avec eux demeuraient immuables, y compris l'éradication définitive de la religion dans la société communiste. C'est précisément au regard de ce qui revêtait la visibilité et l'impact les plus grands sur l'opinion publique que le processus de réouverture des églises, quoique limité, est à considérer comme une confirmation de l'importance significative du changement survenu dans la politique religieuse soviétique.

Le tournant de 1943 avait étendu les espaces de légalité concédés à l'activité religieuse en Union soviétique. Les conséquences d'un tel changement étaient notables sur la vie ecclésiale clandestine. La clandestinité, particulièrement répandue au cours des années 1930, n'avait pas été seulement un choix opéré par des ecclésiastiques dissidents appartenant aux multiples groupes scissionnistes qui s'étaient constitués au sein de l'orthodoxie russe. Elle avait été la forme à travers laquelle de nombreuses communautés ecclésiales, en communion avec le locum tenens, cherchèrent à continuer à mener leur vie religieuse dans les conditions d'extrême limitation des espaces de légalité des années de persécution ouverte ${ }^{48}$. Dans les régions sous occupation allemande, le processus massif d'ouverture au culte des églises avait coïncidé avec la sortie de la clandestinité des communautés paroissiales, alors que

47. Rapport de G.G. Karpov à V.M. Molotov du 5 octobre 1944, 1. 218.

48. Cf. Aleksej L. Beglov, V poiskah « bezgrešnyh katakomb» : Cerkovnoe podpol'e v SSSR [À la recherche des « catacombes sans péché ». La clandestinité ecclésiale en URSS], M. : Izdatel’skij Sovet Russkoj Pravoslavnoj Cerkvi-« Arefa », 2008. 
les moines et les moniales avaient pu réintégrer monastères et couvents et reprendre leur vie religieuse ${ }^{49}$. En Ukraine et en Biélorussie, la vie ecclésiale clandestine avait pratiquement cessé d'exister ${ }^{50}$. Au contraire, après septembre 1943, les fonctionnaires du SPDRPC enregistraient une intense activité ecclésiale de type clandestin dans les territoires qui n'avaient pas été occupés par l'armée nazie. La crainte de telles formes de vie religieuse et de leur diffusion était enracinée chez les dirigeants soviétiques. Les pratiques répressives se poursuivaient à l'encontre des groupes clandestins, mais avec une fréquence en baisse constante ${ }^{51}$.

La nouvelle ligne de politique religieuse modifiait les données du problème. Les communautés et les prêtres non enregistrés étaient poussés par la nouvelle situation à demander la légalisation de leur activité et l'ouverture des églises ${ }^{52}$. La réduction des communautés clandestines constituait un des objectifs principaux de Karpov. Leur insertion dans les espaces de l'activité religieuse concédée à l'Église patriarcale semblait être un moyen plus efficace que la répression. Le président du SPDRPC soulignait à quel point dans les zones où il n'y avait pas ou très peu d'églises on observait une « diffusion en masse d'une liturgie de groupe dans les maisons des fidèles ou à ciel ouvert - dans les cimetières, aux abords d'une église fermée - avec la participation de centaines de personnes ». Ces rites étaient célébrés par des prêtres non enregistrés. Le fonctionnaire soviétique qualifiait ces groupes d'opposants à l'Église patriarcale, condamnée par eux « à cause de son atti-

49. Les études classiques sur la renaissance de l'Église orthodoxe dans les territoires occupés par les Allemands comprennent : Friedrich Heyer, Die Orthodoxe Kirche in der Ukraine von 1917 bis 1945, Köln-Braunsfeld : Müller, 1953 ; Harvey Fireside, Icon and Swastika : The Russian Orthodox Church under Nazi and Soviet Control, Cambridge, MA : Harvard University Press, 1971 ; Wassilij Alekseev, Theofanis Stavrou, The Great Revival: The Russian Church under German Occupation, Minneapolis : Burgess Pub. Co., 1976. On y ajoutera deux volumes de M.V. Škarovskij, Nacistskaja Germanija i Pravoslavnaja Cerkov' (Nacistskaja politika v otnošenii Pravoslavnoj Cerkvi i religioznoe vozroždenie na okkupirovannoj territorii SSSR) [L'Allemagne nazie et l'Église orthodoxe (La politique nazie à l'égard de l'Église orthodoxe et la renaissance religieuse dans les territoires occupés de l'URSS)], M. : Izdatel'stvo Krutickogo Patriaršego Podvor'ja-Obščestvo ljubitelej cerkovnoj istorii, 2002, et Politika Tret'ego rejha po otnošeniju k Russkoj Pravoslavnoj Cerkvi v svete arhivnyh materialov (Sbornik dokumentov) [La politique du Troisième Reich à l'égard de l'Église orthodoxe russe à la lumière des archives (Recueil de documents)], M. : Izdatel'stvo Krutickogo Patriaršego Podvor'ja-Obščestvo ljubitelej cerkovnoj istorii, 2003. Sur une page singulière de cette histoire, cf. Konstantin P. Oboznyj, Istorija Pskovskoj Pravoslavnoj Missii 19411944 gg. [Histoire de la mission orthodoxe de Pskov, 1941-1944], M. : Izdatel'stvo Krutickogo Podvor'ia-Obščestvo ljubitelej cerkovnoj istorii, 2008. Enfin, voir Karel C. Berkhoff, «Was There a Religious Revival in Soviet Ukraine under the Nazi Regime? », Slavonic and East European Review, 78 (3), 2000, p. 536-567.

50. Cf. Beglov, V poiskah «bezgrešnyh katakomb», p. 131.

51. Le dernier cas marquant fut celui qui frappa plus de 1673 personnes déportées des oblasti de Rjazan', Voronež et Orël. Berija dans le rapport du 7 juin 1944 informait Stalin qu'il avait pris la décision de les déporter dans des zones sous surveillance du NKVD en Sibérie. Cf. Rapport de Lavrentij Pavlovič Berija à Iosif Vissarionovič Stalin du 7 juin 1944, soveršenno sekretno [top secret], publié dans Škarovskij, Iosifljanstvo, p. 262-263.

52. Cf. Beglov, V poiskah « bezgrešnyh katakomb», p. 134-159. 
tude loyale envers le pouvoir soviétique et le caractère patriotique de ses activités ». Sans détour, Karpov jugeait ces manifestations dangereuses :

Une grande quantité de croyants fanatiques se trouvant sous l'influence de ces groupes à défaut d'une église légalement consacrée dans leur zone d'activité se distingue fortement de l'attitude des groupes de croyants qui se trouvent sous l'influence du clergé de l'Église légale animé de sentiments patriotiques. Cette condition implique toutes sortes de « récidives », de reprise significative des états d'âme religieux, sous la forme du prétendu « renouveau » des icônes, de la diffusion des «saintes » Lettres, de la célébration de prières aux champs, aux sources, de diverses prédictions, mais aussi d'agitation au sujet de la persécution contre la religion et l'Église en URSS..$^{53}$

Il va sans dire que le président du SPDRPC accentuait le caractère antisoviétique de cette vie religieuse clandestine. De plus, la persistance de formes de religiosité populaire «non officielles », si caractéristiques du monde paysan russe et répandues dans la Russie prérévolutionnaire, était préoccupante. Ces manifestations attestaient la persistance d'un monde rural que les bolcheviks ne comprenaient pas et dont ils méprisaient l'arriération. Face à ces phénomènes, Karpov était favorable à une politique qui eût élargi le champ d'action de l'Église patriarcale afin de réduire celui de la vie religieuse clandestine, plus difficilement contrôlable.

La vie de l'Église russe était caractérisée par une remarquable participation des fidèles. Le rapport de Karpov à Stalin du 19 avril 1944 sur les célébrations de Pâques à Moscou l'atteste de façon significative ${ }^{54}$. Le fonctionnaire soviétique observait qu'une affluence considérable avait été enregistrée dans l'ensemble des trente églises consacrées de la capitale. Il estimait à 120000 le nombre de Moscovites ayant pris part à la liturgie pascale, parmi lesquels, d'après ses renseignements, une moitié était constituée de personnes âgées et l'autre, d'adultes et de jeunes à parts égales. En tout cas, les femmes représentaient $75 \%$ de la totalité. Pour l'oblast' de Moscou, Karpov indiquait également une augmentation des présences aux célébrations de la nuit de Pâques, estimées à 148000 , contre 95000 en $1943^{55}$. Le président du SPDRPC ne manquait pas de relever que dans toutes les églises se tenaient parmi les fidèles des soldats et des officiers de l'Armée rouge en nombre notable.

Le réveil de la vie religieuse et la multiplication du nombre de paroisses soulevaient le problème urgent de la formation de nouveaux prêtres pour combler les

53. Rapport de G.G. Karpov à V.M. Molotov du 5 octobre 1944, 1. 220. Par « renouveau » des icônes, il faut entendre des phénomènes miraculeux par lesquels des icônes en mauvais état ou noircies retrouvent leur aspect originel.

54. Rapport de G.G. Karpov à I.V. Stalin du 19 avril 1944, soveršenno sekretno [top secret], in Odincov, Religioznye organizacii v SSSR nakanune $i$ v gody velikoj otečestvennoj vojny, p. 109-110.

55. Berija avait donné à Stalin et à Molotov des estimations différentes. Le commissaire aux Affaires intérieures avait en fait relevé environ 250000 personnes présentes lors de la liturgie pascale à Moscou, par rapport aux 83000 de 1943, et environ 200000 personnes dans la région, pour 160000 en 1943 : Russkaja Pravoslavnaja Cerkov'v gody Velikoj Otečestvennoj vojny, p. 291-292. 
rangs d'un clergé décimé par les persécutions. Une des principales préoccupations de Sergij après son élection fut d'organiser un système de formation théologique, pour la réalisation duquel Stalin lui avait assuré l'agrément du gouvernement. Le 28 novembre, le gouvernement décida de l'ouverture d'un institut théologique à Moscou et en mai 1944, celle de cours de théologie pastorale à Saratov ${ }^{56}$. En mars 1945, on accordait l'autorisation d'ouverture de cours de théologie pastorale à Kiev, Leningrad, Luck, Minsk, Odessa et Stavropol'. En 1946, il fut permis à tous les cours théologiques d'acquérir le statut de séminaires. L'institut de Moscou devint académie théologique et une autre académie fut ouverte à Leningrad en $1946^{57}$.

Ce fut dans ces années que s'amorça le processus complexe de reconstitution de la vie ecclésiale dans un État et une société qui avaient profondément changé sous la direction du pouvoir bolchevik. L'Église, à un rythme plus lent que celui de la société, subissait les conséquences de l'accélération impulsée par Stalin dans les années 1930, au moment du renouvellement des générations des classes dirigeantes du pays. La fracture provoquée par les persécutions et par l'élimination de la fine fleur de deux générations d'ecclésiastiques et de laïcs orthodoxes était un drame pour une institution qui n'avait pas fait siennes les valeurs de la révolution et du progrès, mais se fondait sur la force de la tradition et sur la transmission de celle-ci d'une génération à l'autre. La perspective de la survie de l'Église dans le régime communiste ne pouvait plus n'être que celle de résister au système dans la défense des formes traditionnelles de vie ecclésiale. Sous le poids du contrôle de l'État, la vie de l'Église impliquait l'effort de rechercher une identité propre au sein de la société soviétique, parmi de nouvelles générations de croyants et dans la fidélité à la tradition.

\section{Triomphe de l'orthodoxie dans la capitale du communisme}

Le 15 mai 1944, le patriarche Sergij mourut subitement dans sa résidence. Un nouveau patriarche fut élu par le concile local de l'Église russe orthodoxe qui se réunit à Moscou du 31 janvier au 4 février $1945^{58}$. 171 délégués, représentant les différentes composantes de l'Église, y compris laïques, prirent part aux travaux du concile ${ }^{59}$. Les organes d'information soviétiques leur accordèrent une attention tout à fait inhabituelle ${ }^{60}$. L'assemblée, qui élut à l'unanimité le métropolite de Leningrad Aleksij, était majoritairement représentative de ce groupe d'évêques

56. Cf. Sergej Gordun, «Russkaja pravoslavnaja Cerkov` pri svjatejših patriarhah Sergij i Aleksij [L'Église orthodoxe russe sous les patriarches Sergij et Aleksij] », Vestnik russkogo hristianskogo Dviženija, n 158,1990 , p. 90.

57. Voir Cypin, Istorija Russkoj Cerkvi 1917-1997, p. 622-630, et Čumačenko, Gosudarstvo, pravoslavnaja cerkov', verujuščie, p. 82.

58. Pour la reconstitution des travaux du concile, voir « Istoričeskie dni », p. 31-85.

59. Cf. Ibid., p. 46-47.

60. Voir dans Žurnal Moskovskoj Patriarhii, n² 2, 1945, p. 3-4 et 8-17, les communiqués et documents officiels du concile publiés par l'agence TASS et par Izvestija. 
restreint convoqués en toute hâte en septembre 1943 pour l'élection de Sergij ${ }^{61}$. La légitimité canonique du nouveau chef de l'Église russe avait été solennellement confirmée par la présence de trois patriarches orthodoxes : Christoforos d'Alexandrie, Alexandros d'Antioche et Kallistrat de Géorgie.

Le concile fut un grand succès de l'Église russe dans le monde orthodoxe. Outre ces trois patriarches, les représentants des Églises orthodoxes de Constantinople, de Jérusalem, de Serbie et de Roumanie, trente-trois délégués au total, se rendirent à Moscou à cette occasion. Dans son discours d'introduction, Aleskij, en qualité de locum tenens, exprima toute sa satisfaction de voir une telle assemblée, qui offrait le visage d'une Église qui voulait et pouvait aspirer à jouer le rôle de guide dans le monde orthodoxe :

Par la grandeur et par la composition de l'assemblée ici réunie, il s'agit vraiment d'un Concile œcuménique, parce qu'ici, on peut dire que c'est toute l'Église orthodoxe, sainte, catholique [sobornaja] et apostolique qui est représentée. Mais limitons avec humilité nos pouvoirs, nous ne jugerons et statuerons que des questions relatives à notre Église orthodoxe russe. ${ }^{62}$

La présence de représentants aussi nombreux et éminents était un signe éloquent de l'attention que les autres Églises accordaient au Patriarcat moscovite. L'espoir que Moscou, avec son Église et son gouvernement, puisse à nouveau jouer son rôle traditionnel de protectrice de l'orthodoxie était très répandu parmi les ecclésiastiques des Balkans et du Moyen-Orient.

Le concile fut la manifestation solennelle de la renaissance de l'Église russe, Toržestvo Russkoj Pravoslavnoj Cerkvi [Le triomphe de l'Église orthodoxe russe], comme le titrait un article de l'organe officiel du Patriarcat ${ }^{63}$. La liturgie d'intronisation du nouveau patriarche célébrée devant une foule de fidèles dans la cathédrale de l'Épiphanie, en présence de cinquante-huit hiérarques, patriarches et évêques, fut un événement vraiment extraordinaire dans la capitale de l'État bolchevik. Karpov, en tant que représentant du gouvernement soviétique, y participa également, de même que les représentants du corps diplomatique et les correspondants étrangers. Le métropolite d'Amérique du Nord et des îles Aléoutiennes, Veniamin (Fedčenkov) écrit, plein d'enthousiasme pour les événements de ces jours qui lui semblèrent miraculeux :

Ce fut comme un Concile œcuménique, comme beaucoup d'entre nous l'ont dit. Mais on ne peut s'empêcher de se demander : notre Seigneur Jésus-Christ, le chef

61. Pour une biographie de Aleksij cf. Aleksandr L. Kazem-Bek, «Žizneopisanie svjatejšego patriarha Moskovskogo i vseja Rusi Aleksija I [Biographie du sanctissime patriarche de Moscou et de toutes les Russies Aleksij I] », Bogoslovskie trudy, n 34, 1998, p. 13-185.

62. « Istoričeskie dni », p. 36.

63. A.Š. [A. Šapovalova], « Toržestvo Russkoj Pravoslavnoj Cerkvi [Le triomphe de 1'Église orthodoxe russe] », Žurnal Moskovskoj Patriarhii, n 2, 1945, p. 86-92. Le terme russe toržestvo a le sens de « solennité, triomphe, fête ». 
de l'Église, n'a-t-il pas transféré son centre à Moscou ? N'est-ce pas le destin de la capitale que de réaliser l'antique prophétie du moine Philothée : "Moscou, troisième Rome » ? Certes, cela oblige encore et encore plus fortement l'Église russe à être dans les faits digne d'une si haute élévation tant au moment historique présent qu'à ceux à venir. Mais les faits sont les faits : une assemblée de toutes les Églises ne pouvait aujourd'hui se tenir qu'à Moscou. ${ }^{64}$

Le 10 avril 1945, le patriarche Aleksij, en compagnie du métropolite Nikolaj et du protopresbytre Nikolaj Kolčickij, chancelier du Patriarcat, furent reçus au Kremlin par Stalin, en présence de Molotov ${ }^{65}$. La rencontre eut le caractère « d'une conversation sur les affaires de l'Église orthodoxe », comme le rapporte Karpov dans une note d'information de novembre $1953^{66}$. Dans un article publié dans le numéro de mai du Žurnal Moskovskoj Patriarhii, le métropolite Nikolaj relate certains détails de la conversation avec le leader soviétique ${ }^{67}$. Au cours de l'entretien certaines exigences de la vie ecclésiale furent évoquées, parmi lesquelles l'élargissement du réseau des instituts d'instruction théologique et le développement de l'activité éditoriale du Patriarcat. La conversation porta aussi sur le thème des relations extérieures de l'Église et en particulier sur le voyage que le patriarche s'apprêtait à faire en Palestine et dans les autres pays du Moyen-Orient. Nikolaj précise que « en ce qui concerne tous les projets et besoins [de l'Église], Iosif Vissarionovič manifesta dans une large mesure sympathie et cordialité, promettant son soutien, y compris futur ${ }^{68}$. La rencontre constituait bien sûr une confirmation solennelle du nouveau cours de la politique ecclésiastique du gouvernement soviétique.

Le concile local de l'Église russe et l'élection du nouveau patriarche représentèrent l'aboutissement, ne serait-ce que symbolique, du chemin parcouru par l'Église sous la direction de Sergij. La normalisation des relations avec l'État avait été réalisée en dépit des conditions du système stalinien. L'Église, tout comme la société soviétique tout entière, était en passe de sortir de trente ans de conflit permanent. Elle en était sortie profondément bouleversée. Une page nouvelle s'ouvrait pour l'orthodoxie russe. À la veille de la conférence de Yalta et à quelques mois de la fin du conflit, l'Église russe s'apprêtait à affronter l'après-guerre, ses gageures et ses devoirs.

64. Žurnal Moskovskoj Patriarhii, n 3, 1945, p. 21-22.

65. La rencontre fut rendue publique le 11 avril 1945 de façon lapidaire dans la Pravda et les Izvestija : le texte du communiqué des Izvestija fut publié dans Žurnal Moskovskoj Patriarhii, $\mathrm{n}^{\circ} 5,1945$, p. 3 .

66. Cf. la note d'information sur la question des audiences du patriarche Aleksij par le camarade I.V. Stalin, sekretno [secret], accompagnée d'une lettre de G.G. Karpov à A.M. Petrokovskij, secrétaire du camarade G.M. Malenkov, du 26 novembre 1953, sekretno [secret], GARF, f. 6991 , op. 1, d. 1013, 1. 175 .

67. Mitropolit Nikolaj, « Na priëme u I.V. Stalina » [En audience chez I.V. Stalin], Žurnal Moskovskoj Patriarhii, ${ }^{\circ}$ 5, 1945, p. 25-26.

68. Ibid., p. 26. 


\section{Quelle liberté pour 1'Église?}

Mais quels espaces le nouveau cours de la politique religieuse concédait-il à l'activité de l'Église et quelles limites imposait-il en contrepartie ? La nouvelle philosophie était : liberté d'action accordée, mais liberté conditionnée, limitée et contrôlée.

Restait au SPDRPC à interpréter la législation en vigueur et à définir les nouvelles normes établissant les activités permises et celles interdites aux paroisses et aux ecclésiastiques. Dans les instructions secrètes approuvées en août 1945 et envoyées aux délégués dans les différentes unités territoriales administratives de l'URSS, les limites du champ d'action concédé à l'Église étaient très clairement établies ${ }^{69}$. Ces indications concernaient avant tout les paroisses et les ecclésiastiques officiellement reconnus suivant les normes adoptées par le gouvernement soviétique. La liste des activités autorisées spécifiait : la possibilité pour les prêtres de célébrer les cérémonies liturgiques dans les églises et chapelles légalement ouvertes ; la convocation et la tenue dans les locaux de l'église de réunions statutaires des organismes paroissiaux ; la collecte auprès des paroissiens d'offrandes à destination exclusive des besoins de la gestion de l'église ; l'organisation de processions autour de l'édifice de l'église, à condition que celles-ci fassent partie intégrante des célébrations liturgiques - il était en particulier fait référence à la liturgie de la nuit de Pâques - , de cortèges funèbres pour accompagner les défunts au cimetière, de processions et de rites de bénédiction de l'eau à l'occasion uniquement des fêtes liturgiques de la Théophanie, c'est-à-dire du Baptême et de la Pentecôte ; la possibilité de sonner les cloches sans restriction aussi bien à l'intérieur des églises qu'aux clochers ; le droit d'administrer et de célébrer les sacrements dans les maisons des fidèles sur invitation de ces derniers. De plus, on accordait aux évêques le droit, mais uniquement sur autorisation préalable des autorités locales de concert avec l'appareil central du SPDRPC, de convoquer congrès et réunions du clergé et des laïcs de l'éparchie. Les activités permises à l'Église étaient toutes soumises à un principe régulateur : si un ecclésiastique avait le droit d'exercer sa fonction, il développait les activités connexes exclusivement au sein de l'institution ecclésiastique (paroisse, monastère, séminaire, éparchie) à laquelle il était affecté.

Le document répertoriait aussi de façon détaillée les activités interdites : créer des caisses de secours mutuel, fonder des instituts d'assistance et organiser des coopératives ; utiliser les biens mis à disposition du culte à des fins autres que la satisfaction des besoins religieux; organiser des cours, des cercles, des groupes de quelque nature que ce soit, sans autorisation du SPDRPC ; ouvrir des bibliothè-

69. Cf. Instrukcija Soveta po delam Russkoj pravoslavnoj cerkvi pri SNK SSSR dlja upolnomočennyh Soveta pri SNK sojuznyh i avtonomnyh respublik, oblastnyh (kraevyh) ispolkomah [Instruction du Conseil pour les affaires de l'Église orthodoxe russe auprès du SNK de l'URSS pour les délégués du Conseil auprès des SNK des républiques de l'Union et des républiques autonomes et auprès des comités exécutifs des oblasti (kraja)], M., 1945, sekretno [secret], p. 10-13, GARF, f. 6991, op. 1, d. 28, 1. 7-8. Les Instrukcii avaient été approuvées par la réunion du SPDRPC du 25 août 1945. 
ques publiques et des salles de lecture ; donner vie à des établissements de repos (sanatorii) et de soin ; organiser des excursions, des camps de jeux, des réunions de jeunes, de femmes, ou autres de ce genre. Il était enfin précisé que tout type d'enseignement de doctrine religieuse dans les établissements d'instruction et d'éducation, tout comme la célébration de rites religieux ou l'ostension d'objets du culte étaient interdits dans l'enceinte des locaux des institutions et entreprises d'État, coopératives, publiques.

Les instructions secrètes du SPDRPC traçaient les limites à l'intérieur desquelles la vie de l'Église devait se cantonner. La possibilité d'une intervention publique quelle qu'elle soit de l'Église dans la vie de la société soviétique était exclue. Son activité devait rester strictement liée à l'exercice du culte. L'espace autorisé était celui de la satisfaction des besoins religieux, qui d'après les schémas idéologiques soviétiques, s'étioleraient une fois le processus de transition au communisme achevé. C'était là une ligne de continuité dans la politique religieuse bolchevique : le culte représentait l'unique activité licite de l'Église. Pourtant, on ne peut pas ne pas le noter comme un changement par rapport à la furie iconoclaste de la lutte antireligieuse des années d'avant-guerre, quand les croyants orthodoxes étaient persécutés jusque dans l'espace de leur liturgie. Un tel espace était désormais garanti par les autorités soviétiques, également pour des manifestations qui avaient été précédemment violemment réprimées par le pouvoir bolchevik, comme par exemple la sonnerie des cloches ${ }^{70}$. Dans la société soviétique se profilait la possibilité d'une présence de l'Église centrée sur la liturgie. Il s'agissait bien sûr d'une limitation restrictive de la vie ecclésiale. Et pourtant c'était aussi la possibilité, pour une Église qui, historiquement, avait fait de la vie liturgique le trait principal de sa présence dans la société, d'élaborer une stratégie de résistance qui, dans un cadre de cohabitation avec le pouvoir soviétique, fît justement de la liturgie un de ses points de force majeurs.

À la phase de résistance ouverte d'une Église encore forte par rapport au nouveau pouvoir bolchevik et à celle d'extrême faiblesse qui suivit, entre persécutions et vie clandestine, succéda après 1943 l'ère de la cohabitation avec un régime que la débâcle de l'armée hitlérienne faisait apparaître comme triomphant. La cohabitation était organisée aux conditions posées par Stalin. C'était au pouvoir seul de dicter les règles du jeu. Cela était clair aussi pour les ecclésiastiques à la tête de l’Église russe pendant ces années. Le compromis proposé par Stalin en 1943 avait instauré un rapport de coopération totalement asymétrique. C'était une saison aux tons moins vifs que celles qui l'avaient précédée. L'heure n'était plus aux stratégies de résistances : du choix de ne pas se plier ou subir la persécution, en passant par celui de la clandestinité. L'Église se trouvait dans la position de devoir affiner sa propre capacité à tirer le meilleur des espaces de manœuvre qui lui étaient concédés par le pouvoir soviétique afin de chercher à renforcer la vie ecclésiale et de tenter

70. Sur la campagne pour la suppression des cloches, voir Luukkanen, The Religious Policy of the Stalinist State, p. 70-79, et O.Ju. Vasil'eva, Russia martire : La Chiesa ortodossa dal 1917 al 1941, Milan : La Casa di Matriona, 1998, p. 199-206. 
de lui garantir un avenir. C'était une stratégie qui passait nécessairement par la ligne de crête glissante de la collaboration avec les autorités d'un régime qui avait été persécuteur et continuait d'être hostile, une stratégie qui s'inscrivait dans la double perspective de redonner vie à une réalité ecclésiale réduite à sa plus simple expression et de pouvoir disposer, le moment venu, des ressources minimales indispensables à une renaissance de l'Église.

(traduit de l'italien par Élise Gaignebet)

Dipartimento di Studi Storici Geografici Antropologici

Università Roma Tre

roccucci@uniroma3.it 